\title{
Towards Morphogenesis in Architecture
}

Stanislav Roudavski 


\section{Towards Morphogenesis in Architecture}

Stanislav Roudavski

Procedural, parametric and generative computer-supported techniques in combination with mass customization and automated fabrication enable holistic manipulation in silico and the subsequent production of increasingly complex architectural arrangements. By automating parts of the design process, computers make it easier to develop designs through versioning and gradual adjustment. In recent architectural discourse, these approaches to designing have been described as morphogenesis. This paper invites further reflection on the possible meanings of this imported concept in the field of architectural designing. It contributes by comparing computational modelling of morphogenesis in plant science with techniques in architectural designing. Deriving examples from case-studies, the paper suggests potentials for collaboration and opportunities for bi-directional knowledge transfers. 


\section{Introduction}

Engineers of The Water Cube, a swimming pool in Beijing constructed for the 2008 Olympics [I], considered a variety of arrangements from living cells to mineral crystals before implementing a structure resembling that of soap bubbles. (The trend for Voronoi or similar cellular geometry is evident in other projects, such as the Federation Square [2] and Melbourne Recital Centre [3] in Melbourne, or ANAN, the Japanese noodle bar [4].) The architects and engineers created this structure by generating an infinite array of digital foam and then subtracting from it the building's volumes. Computational procedures automatically created the building's geometry, performed structural optimization and produced construction drawings. This high-profile example is interesting in the context of this paper because it demonstrates a successful implementation of a large-scale cellular structure in a project that is acclaimed for its visual impact as well as for its performance. However, The Water Cube project also misses an opportunity because it does not utilize the potential of its bubble-like structure to adapt to environmental conditions or other criteria. While it might be that The Water Cube project had no need for adaptability, in other circumstances, this potential can be beneficial. In contrast, many cellular structures in nature are highly adaptable and, therefore, can suggest further development for their architectural counterparts.

This paper expects that complex, non-uniform structures will become increasingly common in architecture in response to the growing utilization of parametric modelling, fabrication and mass-customisation. New challenges and opportunities that the designing of such structures brings are without direct precedents in architecture. Yet, such precedents do exist in nature where structurally complex living organisms have been adapting to their environments for millions of years. Comparing the formation of cellular structures in biology and in architecture, this paper looks for approaches to architectural designing that can extend architects' creative repertoire while retaining the automation that made The Water Cube possible.

Using case-studies operating with cellular structures, the paper aims to provide a brief comparison between the understandings of morphogenesis in biology and architecture. This comparison can help to highlight the similarities, differences and potentials for the two research communities. While as disciplines, architecture and biology share some similarities (e.g., both deal with entities operating in context and both use computational models), the differences in goals, epistemology, knowledge base, methods, discourse and institutional organization are significant, making communication and collaboration difficult. Despite the differences and difficulties, direct collaborations between biology and architecture are necessary not only in the narrow context of the present discussion but also because they can help to orient designing towards ecologically compatible outcomes. Another, equally exciting outcome of such collaborations will be 
in further contributions towards creative inspiration. Unlike scientists such as biologists (but not unlike biotechnologists and bioengineers who are also designers), designers (including architects) focus not on the study of the existing situations but on the consideration of possible futures. Working in complex situations and typically looking for futures that cannot be derived from the past or from the laws of nature, designers search the present for variables that can be modified. [cf. 5, pp. 28, 29] Variables accessible (known, found) to a designer in a given situation add up to a design space [6]. Unconventional, lateral, associative moves are often necessary to expand this space and to find in it innovative outcomes. As history and the recent experimentation confirm, bioinspiration can be a rich and rewarding source of such innovation.

A better understanding of biological morphogenesis can usefully inform architectural designing because I) architectural designing aims to resolve challenges that have often already been resolved by nature; 2 ) architectural designing increasingly seeks to incorporate concepts and techniques, such as growth or adaptation, that have parallels in nature; 3 ) architecture and biology share a common language because both attempt to model growth and adaptation (or morphogenesis) in silico. In a reverse move, architecture and engineering can inform the studies in biology because I) components of organisms develop and specialize under the influence of contextual conditions such as static and dynamic loads or the availability of sun light 2) in biology as in architecture, computational modeling is becoming an increasingly important tool for studying such influences; 3) architecture and engineering have developed computational tools for evaluating and simulating complex physical performances (such as distribution of loads, thermal performance or radiance values); and 4) such tools are as yet unusual or unavailable in biology.

\section{Morphogenesis in architectural design}

Morphogenesis is a concept used in a number of disciplines including biology, geology, crystallography, engineering, urban studies, art and architecture. This variety of usages reflects multiple understandings ranging from strictly formal to poetic. The original usage was in the field of biology and the first recorded instances occur in the second half of the 19th century. An earlier, now rare, term was morphogeny, with the foreign-language equivalents being morphogenie (German, 1874) or morphogénie (French, 1862). Geology was the next field to adopt the term in the 20th century.

In architecture, morphogenesis (cf. "digital morphogenesis" or "computational morphogenesis") is understood as a group of methods that employ digital media not as representational tools for visualization but as generative tools for the derivation of form and its transformation [7] often in an aspiration to express contextual processes in built form [8, p. 195]. In this inclusive understanding, digital morphogenesis in architecture bears a 
largely analogous or metaphoric relationship to the processes of morphogenesis in nature, sharing with it the reliance on gradual development but not necessarily adopting or referring to the actual mechanisms of growth or adaptation.

Recent discourse on digital morphogenesis in architecture links it to a number of concepts including emergence, self-organization and form-finding [9]. Among the benefits of biologically inspired forms, their advocates list the potential for structural benefits derived from redundancy and differentiation and the capability to sustain multiple simultaneous functions [10]. Hensel and Menges [ $\mathrm{I}$ I] also argue that, in contrast to homogenized, open-plan interior spaces produced by modernist approaches, the implementation of locally-sensitive differentiation, achieved through morphogenetic responsiveness, can produce more flexible and environmentally sound architecture.

In his discussion of how this line of thinking can be developed further, Weinstock [12, p. 27] calls for "a deeper engagement with evolutionary development and a more systematic analysis of the material organisation and the behaviour of individual species." Responding to this call, further discussion in this paper focuses on a comparison between two computational approaches towards a procedural generation of cellular structures in architectural design and in botany. This focus on specific casestudies allows for closer examination of some essential concepts and provides practical examples of already-existing computational solutions in the field of plant science that can be re-utilised or serve as suggestive guidelines in the field of architecture.

\section{I Example I: Procedural production of The Parasite's structure}

The first case-study discussed in this paper is The Parasite research project [13-16] that was developed for the International Biennale of Contemporary Arts. The event took place in Prague in 2005.

The Parasite installation consisted of a physical structure and an interactive audio-visual system designed to operate in the Prague's Museum of Modern Art. The installation fit into an existing stairwell (Figure 2 and 3) that served as a primary circulation hub.

The Parasite project considered whether and how design computing can support distributed creativity in place-making. Can procedural techniques sustain inclusive designing and production? Can it be useful to rethink placemaking as one continuous performance that encompasses designing, constructing and inhabiting? Can procedural techniques help to develop and seamlessly integrate built forms, interactive new media and human behaviours? The outcomes of the project included an innovative research method, an original theoretical approach to place-making and suggestive place-making precedents. 


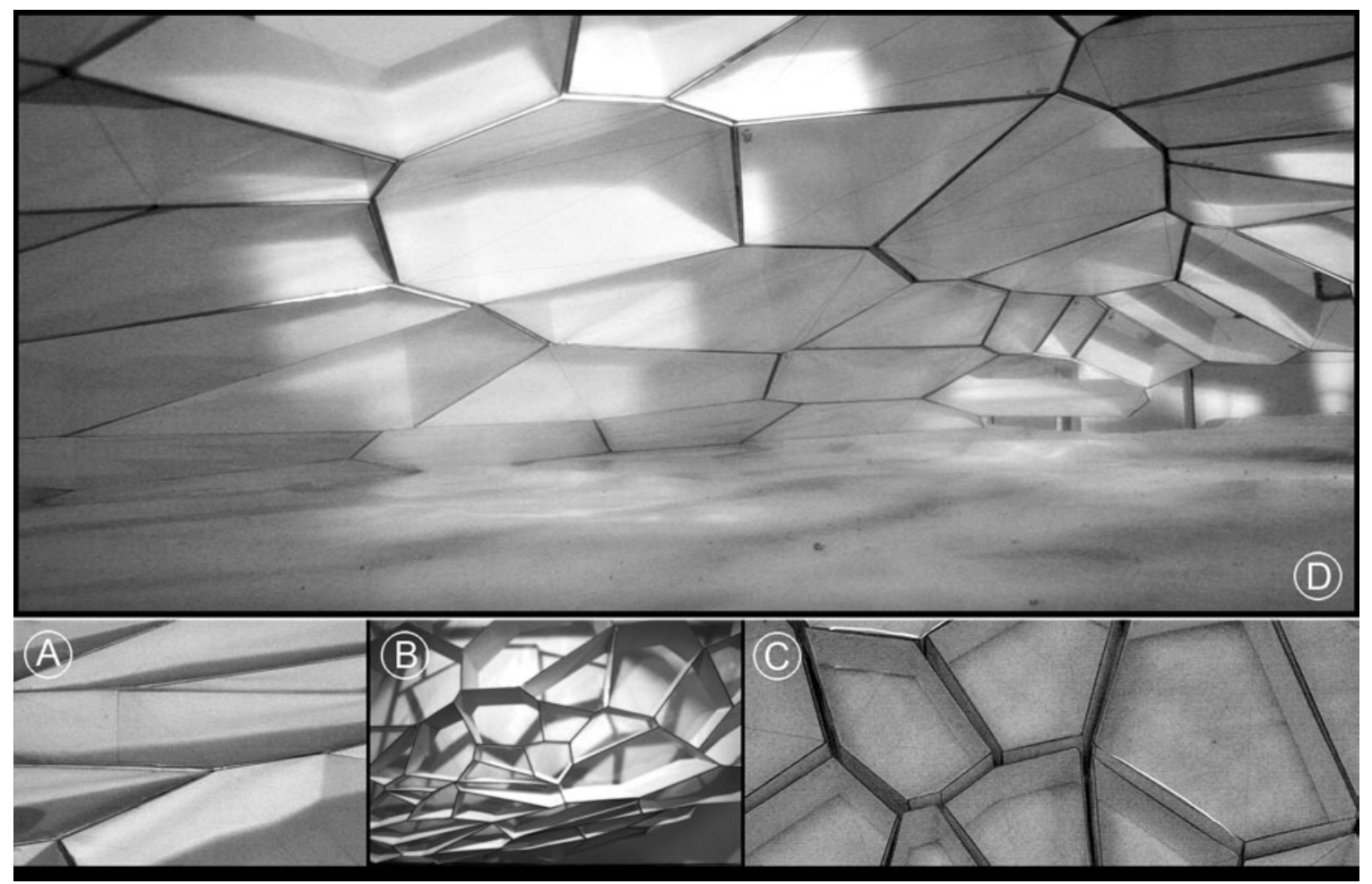

Research context

The Parasite project's research questions emerged from a broader research context. Briefly, The Parasite project was one of several case-studies that I used to develop an understanding of places as performances; a theoretical stance that I termed "the performative-place approach" [17]. This approach emphasizes the performative in contrast with attitudes that prioritise the making of buildings rather than habitats. The performative-place approach also seeks to progress from backwards-looking, romantic, essentialist and exclusionary understandings of places that emphasize traditions and are suspicious of technology. Instead, I emphasise that places are dynamically constructed by their participants; contingent on the idiosyncratic involvements of these participants; multiplicious, fuzzily bounded or even global; and dependant on technologies. (I adopt an inclusive understanding of the term technology as a way of knowing how. This understanding accepts as technology not only the obvious recent candidates such as machines or computers but also such achievements as human speech or writing.)

Having established this theoretical foundation, I further explored the case-studies searching for creative strategies able to stage placeperformances. According to the performative-place approach, architects cannot produce ready places but can engender place-making performances and influence their growth with provocative, inclusive and collaborative
A Figure I. The Parasite project. (A) Visual, non-repeating striation produced by cell-walls seen in perspective resembles complex patterns produced by natural phenomena. (B) A fragment showing a detail of the cellular structure and its capabilities for local curvature and cell-wall variations. (C and D) Cells arranged to be assembled into a patch. Similarly to the cells in plants (see Figure 7), The Parasite's cells were assemblies of walls. (Photographs by Giorgos Artopoulos and Stanislav Roudavski) 
creative strategies. These strategies have to rely on distributed, polyphonic and campaigning understandings of creativity rather than on the stillprevalent interpretations privileging individual genius or supernatural inspiration. This inclusive understanding of creativity acknowledges contributions from human as well as from non-human participants. These participants can be hidden, unwitting, unwilling or unequipped for a dialogue. Consequently, I) finding out who (or what) participates (or acts) in a given situation; 2) understanding the language they speak and establishing mechanisms for translation; 3) soliciting their participation; and 4) providing a framework for their useful contributions are all non-trivial challenges. My research explores how architectural design-computing with its emerging generative, adaptive and heuristic techniques can provide for these creative collaborations. Computing can contribute to these goals in a number of ways, for example by supporting design strategies that focus on open-ended collaborative exploration of opportunities, enabling development through rehearsals, making possible non-reductive manipulation of complexity, empowering dynamic evaluation of given situations and projected outcomes, helping in translation between heterogeneous participants and domains of knowledge, sustaining not only graphic but also performative thinking and learning, providing tools for campaigning and sustaining environments that can simultaneously co-host multiple worldviews and voices.

\section{Focus and limitations}

The Parasite project can help to illustrate the comparison between interpretations of morphogenesis in biology and architecture because its development incorporates computer-supported design techniques currently under active discussion in architecture while also implementing a cellular structure that resembles those found in biology. One example in a diverse field, The Parasite project is an illustration of limited generality. As a smallscale construction it did not have to engage with many issues essential for large architectural projects. Narrowing its comprehensiveness still further, this article focuses on the generation of sculptural form and does not consider in detail social, cultural, structural and other implications of such structures or their modes of production (I have engaged in this broader discussion elsewhere [17]). However, by providing recognizable examples from the domain of architecture, The Parasite project helps to suggest possible architectural usages for the techniques of computational modelling in biology as discussed below. The aim of this paper is not to insist that these examples amount to directly useable and useful architectural-design techniques but instead to illustrate how a closer engagement with biological know-how can deepen and concretize the existing discourse on morphogenesis in architecture. 


\section{Interrupted automation}

Developing The Parasite, we used dynamic simulation and time-based processes to produce computational models of complex cellular structures. An important characteristic of our generative process was that it consisted of several distinct stages. At each stage of the process, designers chose an intermediate version to survive and be used in the next stage. Designers selected surviving versions according to criteria formulated in response to the research questions and the logic of physical construction. The influences on choices were both intuitive (form, proportions, imagined cultural and artistic impact) and analytical (production requirements, construction technique, time, finances, logistics, formal novelty, potential for further research and development). The process can be categorized differently but we found it useful to think about it as a multi-part procedure that involved I) establishment, using guiding planes; 2 ) exploration, using dynamic curves and surfaces; and 3) refinement, using repelling/attracting fields and particles [16]. These three stages process produced two irregular, topologically cylindrical surfaces and were continued by two more stages [14] that 4) distributed points along the surfaces; 5 ) generated Voronoi cells around these points; 6) created cell-walls and cell-skins and 7) prepared the cell components for robotic manufacturing.

The resulting computer-supported workflow coordinated the generation and adjustment of several digital models (Figures I-6) that, in combination, supported automatic local variation in response to surface curvatures, lines of sight, positions of projectors and other parameters (Figure 5). Heuristic, iterative development of the final, production-ready digital components incorporated multiple inter-stage opportunities that allowed designers to analyse and adjust the intermediary outcomes. The resulting hybrid approach combined computer automation with human guidance and proved to be suitable to the challenge.

In many situations, this type of hybrid multi-stage process can be beneficial because it allows designers to offset limitations of computational processes that cope well with clearly defined operations but struggle with indeterminacy and cannot pass judgements in situations that involve cultural, social, aesthetic and other inherently human concerns.

In contrast, prolongation of an automated generative process's continuity can also result in significant benefits. For example, computer-sustained automation can enable manipulation of otherwise unmanageable and even unimaginable complex situations. In another creative benefit, the ability to propagate conceptual changes through parameters helps to evaluate consequences of creative moves, for example when adjustments made at the beginning of a generative sequence can automatically reconfigure the arrangement of manufacturable parts.

Might it be possible to combine the creative benefits of modular, multistage workflows with those given by the continuity of automation? This 
paper suggests that this can be achieved if the designers gain a capability to introduce variations without stalling the automation or overwriting the effects of previous manual interferences. In addition to manual adjustments, the capacity for the cumulative layering of influences can also permit the combining of heterogeneous manual and automated processes. These processes can be driven by different types of data or mechanisms. To achieve this extended capacity for non-destructive control, the generative process has to be able to constrain interferences. This constraining can utilize different types of rules and, for example, be spatial - with changes occurring only in a particular region - or logical - impacting only certain types of elements. This paper suggests that examples of growth and adaptation in living organisms can provide examples of complexly layered processes that can be flexibly responsive to many simultaneous influences.

\section{Hierarchical flatness}

Reading about conceptual models of biological morphogenesis, I realised that adaptability of The Parasite's computational model was constrained by its flat hierarchy. This hierarchical flatness is not unique to The Parasite but is also characteristic of other architectural examples, for example of The Water Cube's computational model. The Parasite's structure can be made more sophisticated if additional variability is introduced on the infra-cell, cell and the supra-cell levels. Infra-cell variable properties could include, for example, cell-wall thicknesses or skin transparencies. Some variability of this type already exists in the computational model of The Parasite's structure where cells can have varied wall lengths, heights and orientation (e.g., see Figure 4 and Figure 5). Such variable attributes could produce significant qualitative differences if the system could support additional variation on the cell level, for example by supporting cells of different type and or making cells capable of distinct, type- and location-specific functions. The Parasite's structure did not support any intermediary supra-cells levels that could be likened to organs in living organisms. The only true supra-cell level in The Parasite's structural hierarchy is the complete shell (Figure 2 and Figure 3) that can be considered an equivalent to a complete organism. For the purposes of construction, the shells were subdivided into patches that could fit into existing openings in the host building but these intermediate subdivisions were not utilised for form generation.

This paper suggests that the conceptual models of hierarchical organisation of living organisms can usefully inform generative approaches to designing in architecture. For example, in The Parasite, shells or video projectors could be considered organs residing on supra-cell levels of the hierarchy and thus procedurally linked with the rest of organisational structure. 


\section{Static structure}

The computational model of The Parasite's cellular structure gained its capacity for adaptation largely through rapid regeneration of multiple versions considered within multi-stage design process. The Parasite's computational model did not have an automated capacity for growth and adaptation. Unlike in biology, the digital model of the structure was not generated through expansion and proliferation of cells. Instead, each automated procedure comprised one discrete step in the hybrid generative process. Within these discrete steps, operations happened sequentially, however the order of operations within sequences did not relate to the logic of growth or the needs of adaptation. For example, one computational procedure distributed points on the surfaces of the shells (there points were subsequently used as centres for the Voronoi cells). The procedure distributed the points by creating each point individually and positioning it among the existing points while observing constraints on inter-point distances. After the number of points specified by the designer was distributed along the shell, the procedure ended and no further adjustments of point positions or point numbers were possible without a complete regeneration. The point arrangement responded to the initial conditions but was otherwise static (for the technical details on the methods used for point distribution and cell-generation in The Parasite project, see [14]). The capacity for quick regenerations did allow heuristic adjustments and a degree of adaptation via versioning. However, gradual and local adjustments achieved via versioning have limited flexibility because they interrupt automation and often necessitate complete regenerations. Such complete regenerations can be excessive and counterproductive where only local changes are necessary. A regenerated structure often can achieve improvements in some areas but eradicate already-acceptable solutions in others. This paper suggests that biology can supply examples of growth systems able to inspire more flexible, dynamic and integrated organisations of automated and hybrid generative architectural workflows.

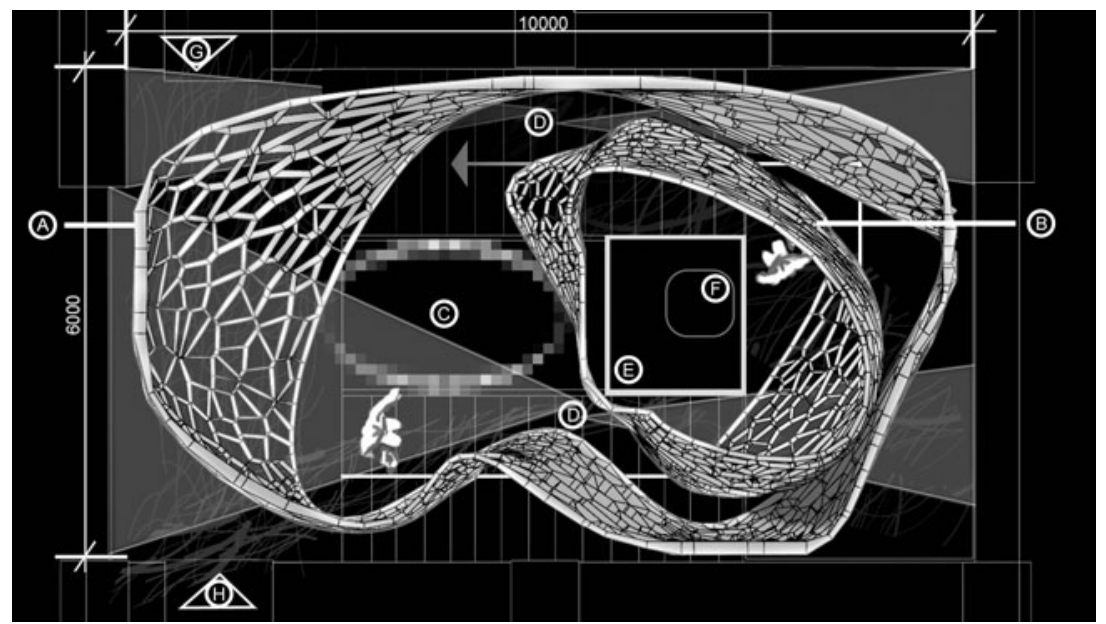

Figure 2. The Parasite. Plan view as designed. We formed the shells using dynamic curves. [A] Outer shell. [B] Inner shell. [C] Approximation of the area observed by the computer-vision system. [D] Video projections. [E] Disused lift. [F] Computers and the sound system. [G] Doors to the Main Hall. [H] Street entrance. (Digital rendering by Giorgos Artopoulos and Stanislav Roudavski [14]) 


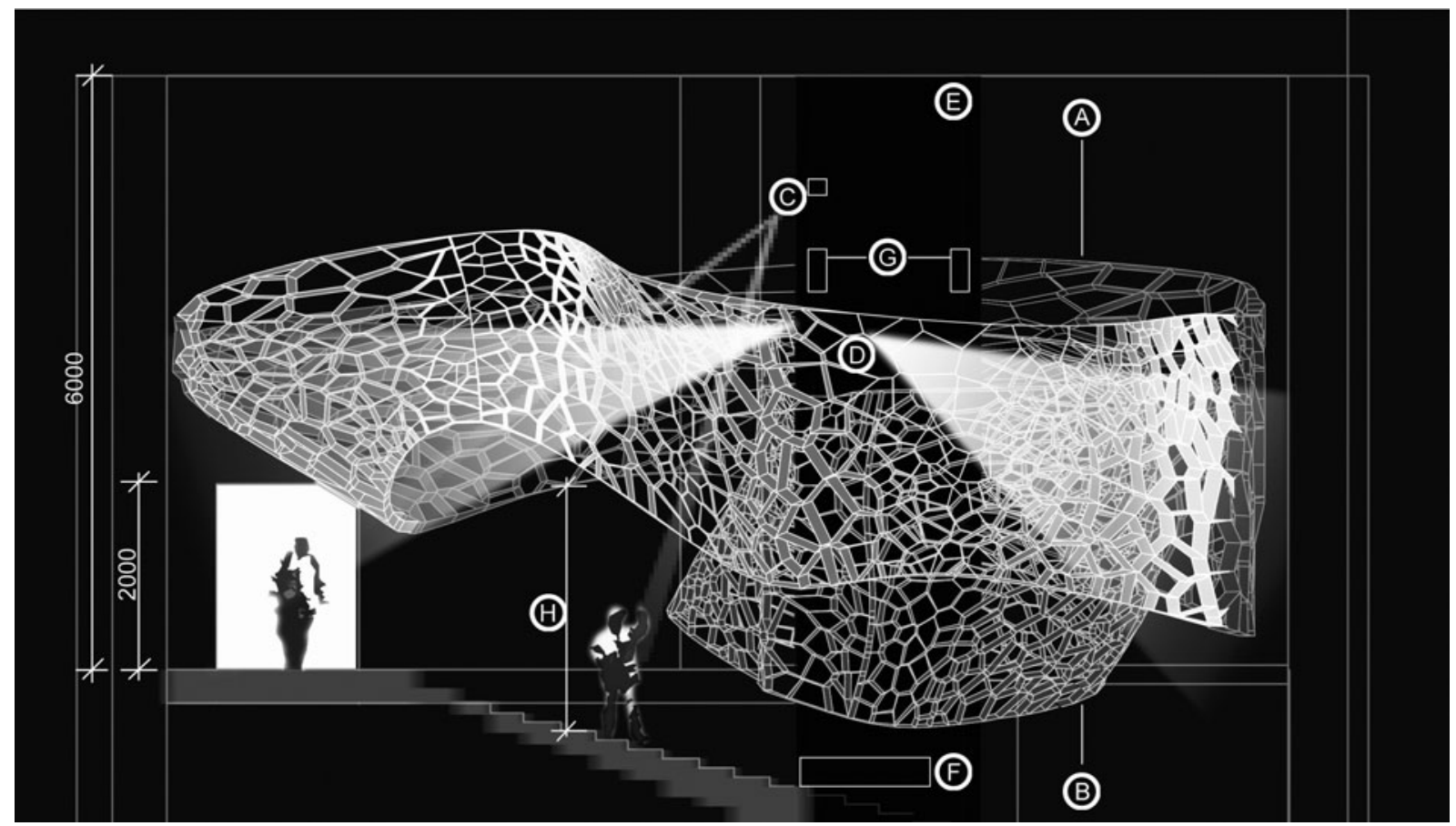

$\Delta$ Figure 3. The Parasite. Side view as designed. We achieved the flattened areas along the walls using particle-based soft bodies. The outer shell had curvature-based cell-wall width differences obvious along the top rim. The inner shell had a constant cell-wall width. [A] Outer shell. [B] Inner shell. [C] Approximate area observed by the computer-vision system. [D] Video projections. [E] Disused lift. [F] Computers and the sound system. [G] Speakers. [H] We made sure that the pedestrian passage remained unobstructed. (Digital rendering by Giorgos Artopoulos and Stanislav Roudavski [14])

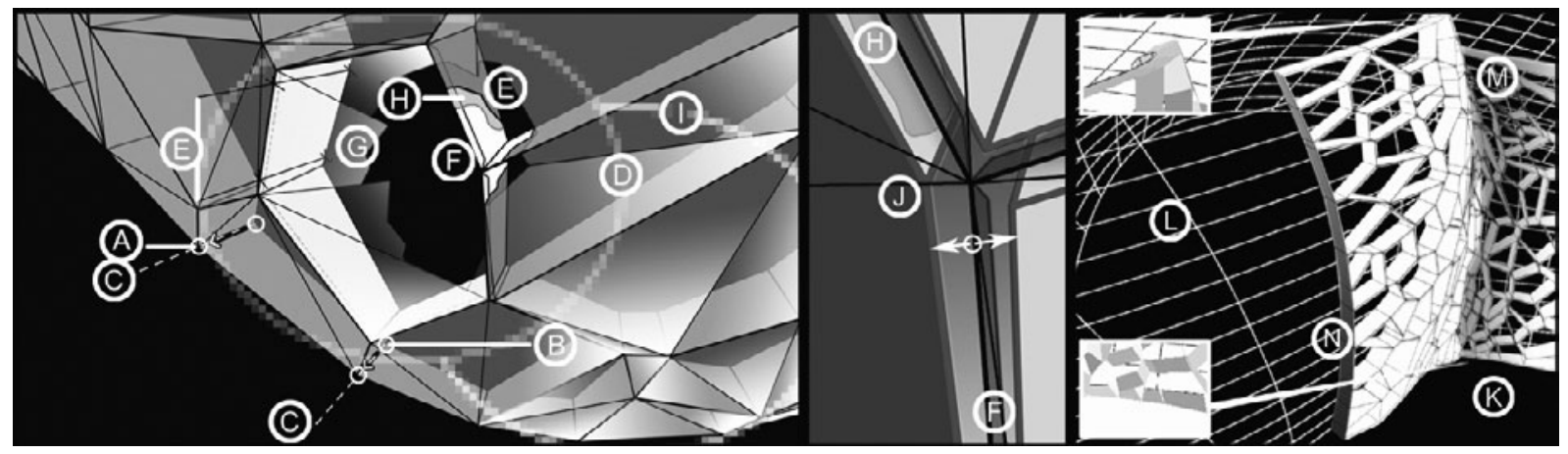

$\Delta$ Figure 4. The Parasite. Structure and detailing of the cells. [A] Offset point, shown circled. [B] Base point, shown circled. [C] Direction of offset along the normals, shown as dashed lines. [D] Cell. [E] Cell-wall with varying width. [F] Cell-skin flaps. [G] Cell-skin. [H] Glue. [I] Non-planarity of cell-walls and cell-skins, shown as shading changes. [J] Cell-wall insets. [K] Outer shell. [L] Input surface. [M] Generated cells. [N] Shell seam. (Digital renderings by Giorgos Artopoulos and Stanislav Roudavski [14]) 


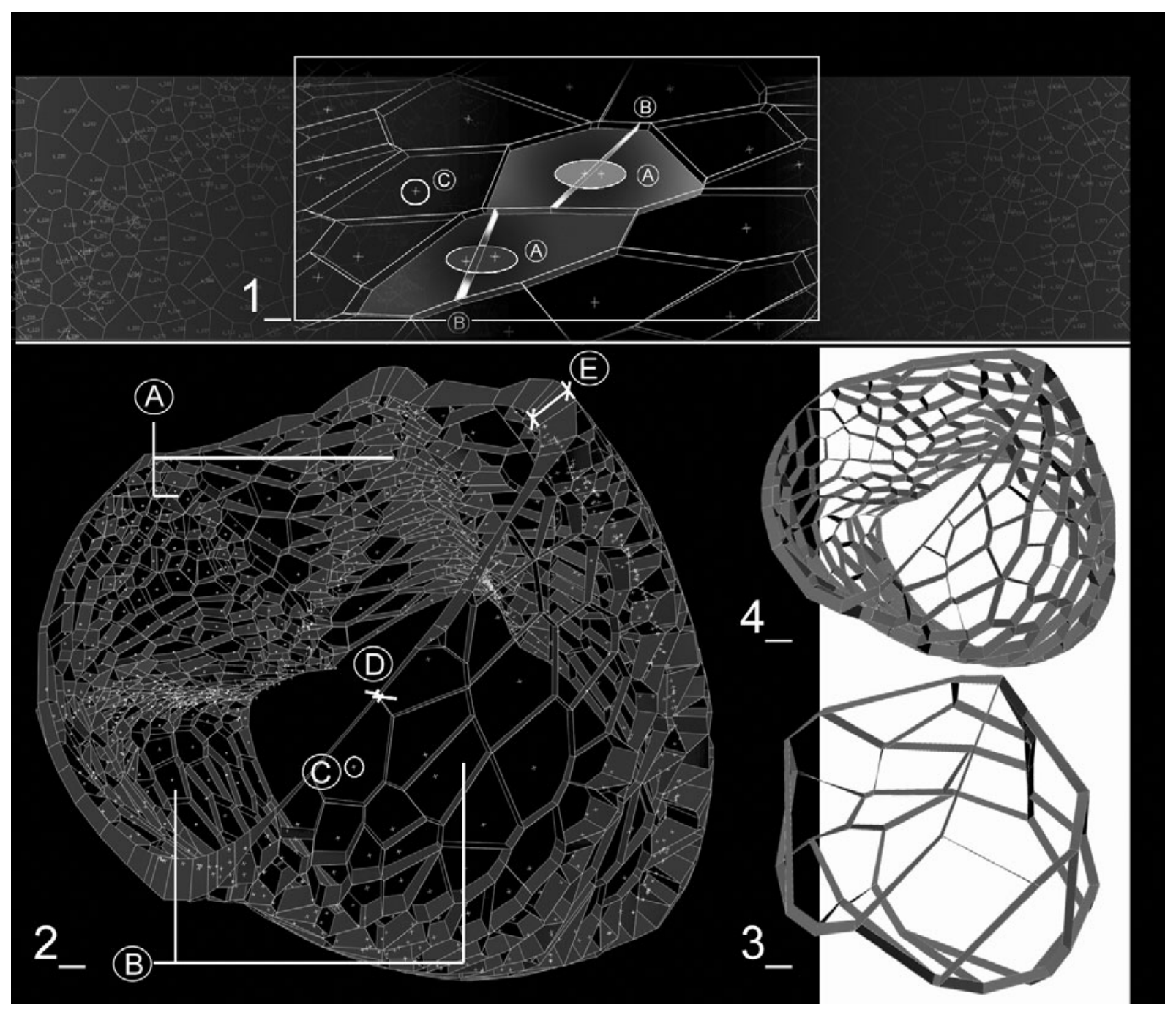

A Figure 5. The Parasite.Variations in shell structure, inner shell. We used two methods to distribute the points: I) Constant method attempted to distribute a given number of points on a given surface uniformly so that the resulting distances between neighbouring points were close to equal; 2) Curvature method related the point density to the amount of surface curvature so that the higher surfacecurvature resulted in the higher point-density. We used a combination of distribution methods to generate the point cloud for the outer shell. Combining the methods allowed us to constrain the minimum distance between points to the values suggested by the structural capacities of the cardboard. [I] Fragment showing the structural consequences after we added two point clouds with different point distributions. [I_A] The scripts controlled the minimal distances between points during point distributions for each point-cloud separately. When we added one point cloud to the other, the distances between some point-pairs could be smaller than these thresholds. [I_B] An extra cell-wall inserted between the two points. [I_C] A point in a cloud. [2] An image showing structural variations. Settings: two pointclouds used, first cloud - Constant method, I50 points; second cloud - Curvature method, 700 points; curvature-dependent cell-wall height, minimum cell-wall height $-50 \mathrm{~mm}$, maximum cell-wall height $-250 \mathrm{~mm}$. [2_A] Formations of high density at high-curvature areas. [2_B] Low-curvature areas. [2_C] A point. [2_D] High cell-wall. [2_E] Low cell-wall. [3] One point-cloud used - Constant method, 20 points; Constant method for cell-wall height, I50mm. [4] One point-cloud used - Constant method, 200 points; Constant method for cellwall height, I50mm. (Digital renderings by Giorgos Artopoulos and Stanislav Roudavski [16]) 
Figure 6. The Parasite. Voronoi cellpatterns. Areas with extremely high or extremely low curvature could break the dependency we implemented between curvature and point density. When the algorithm used the whole array of sampled curvature-values, the script tended to produce confined areas with high density while distributing the points on the rest of the surface almost uniformly. Thus, it was necessary to introduce an intermediate representation that would allow designers to visualize the sampled curvature values and to clamp the value range if necessary. To achieve this, the script normalized the array of curvature values to fit the 0 -to- 100 range and then displayed it as a graph [A]. A graph showing sampled curvature values and clamping of the curvature range. Responding to the graph, designers could clip lower and/or higher portions of the range discarding part of the data. [B] Innershell Voronoi pattern in XYZ space.

[C] A fragment showing variable densities. [D] A fragment showing local variations produced after we added one of the two point-clouds to the other; see the narrow cell in the central area. $[\mathrm{E}]$ Voronoi tiles in the UV space. (Digital drawings and renderings by Giorgos Artopoulos and Stanislav Roudavski [14])

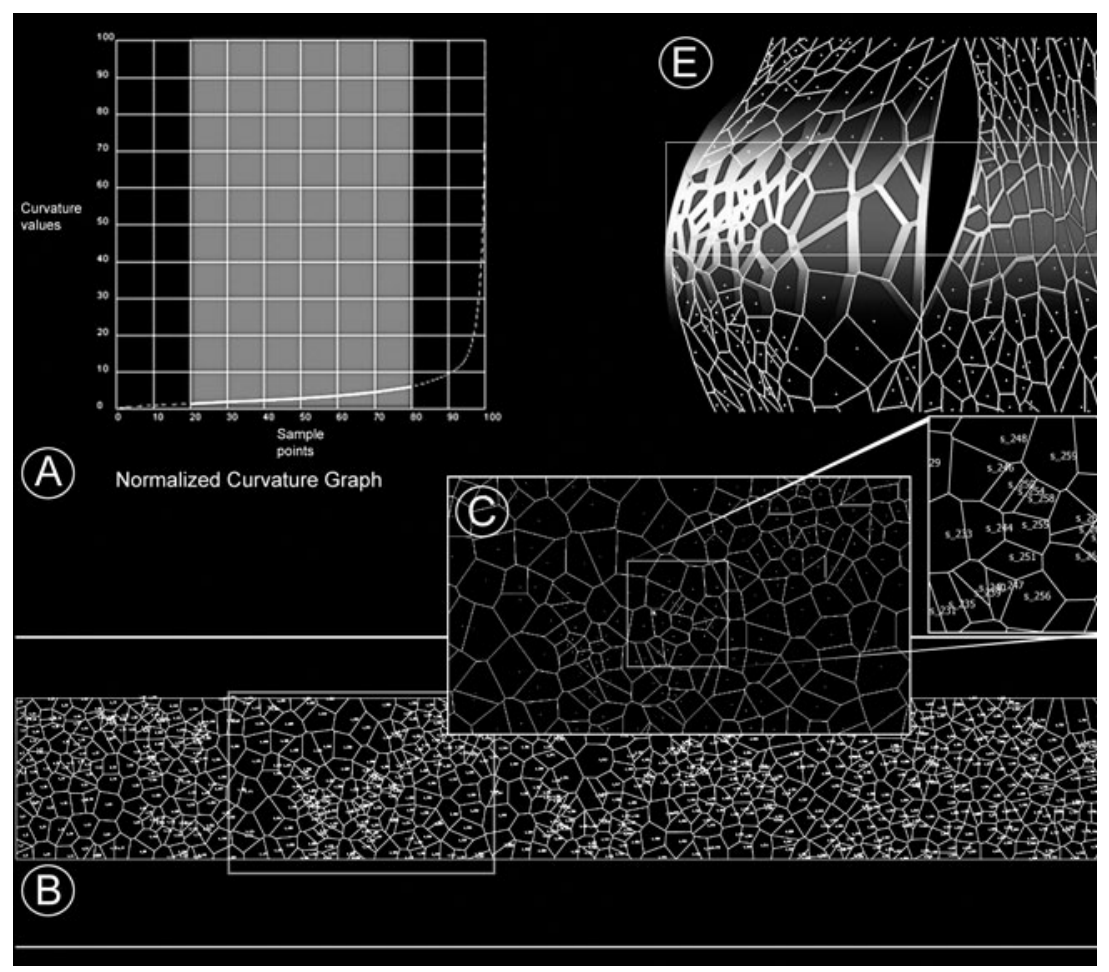

From architecture to biology

In an effort to advance the design methods and techniques used for the generation and control of complex architectural structures, this paper compares form-making in The Parasite project to the emergence of form in biology, and, more specifically, in plant morphogenesis. The subsequent sections explain the differences and similarities between the two processes highlighting possible usages and benefits. The results are suggestive in the architectural context because while structures similar to that utilised in The Parasite project (and in fact often considerably less sophisticated projects) are becoming more common, their implementations are yet to fulfil their potential.

\section{Morphogenesis in biology}

In biology, "[t]he word 'morphogenesis' is often used in a broad sense to refer to many aspects of development, but when used strictly it should mean the molding of cells and tissues into definite shapes" [18, p. 433]. In accordance with this strict definition, botany understands morphogenesis as the formation of shape and structure via a coordinated process that involves changes in cell shapes, enlargement of cells and proliferation by mitosis [19, p. 78]. Furthermore, "[i]n biology the word "morphogenesis" [can be] used to refer either to (i) the structural changes observed in 
tissues as an embryo develops or to (ii) the underlying mechanisms responsible for the structural changes" [20, p. 29]. Both understandings can be of interest and inspiration for architects, despite the fact that a literal importation of biological structures or processes into architectural design is usually not feasible, meaningful or desirable. For example, while the expression "underlying mechanisms" in the definition can refer to a variety of processes, biology also uses a much more narrow concept of 'mechanism' that "connotes a sequence of events that takes place at a molecular level and that can be explained by interaction of molecules that follow the ordinary laws of physics and chemistry" [23, p. 8]. The particulars of events at this level are not likely to be of direct relevance to architectural design. However, the overarching logic of these exchanges might be suggestive in the design of the control mechanisms for complex and dynamic arrangements.

Morphogenesis is one of several processes typical for living organisms. Apart from morphogenesis, these processes include growth, repair, adaptation and aging. Transferring knowledge of these processes into designing might be also productive, especially in relationship to architectural structures with dynamic capacities. However, the discussion of these additional biological processes or mobile buildings is beyond the boundaries of this paper that, instead, focuses on the development of form occurring during the design stage.

Plant morphogenesis is a very complex process that involves many types of control mechanisms. The study of these mechanisms via direct experimentation and reverse engineering is very difficult and time consuming. Therefore, developmental biologists increasingly experiment with mathematical and computational models that allow them to simulate, understand and predict control mechanisms. This existing interest in computational modelling can serve as a translating device between the relevant processes in biology and architecture.

\section{I Example 2: Computational models of plant morphogenesis}

Unlike the flat structural hierarchy of The Parasite, the structural organisation of plants features units of various types and sizes, for example cells, tissues and organs. Interactions between these entities combine into various regulatory mechanisms [21, 22]. Multiple conceptual descriptions of plant organisation can be attempted and a rigorous, formal description of such an organisation is a necessary prerequisite for the computational modelling of interactions between various parts of a plant.

Biological morphogenesis is a difficult subject to study because it is very complex and dynamic. In the comparatively recent era of molecular biology, "morphogenesis, the deep developmental question that held the centre stage of embryological thought for over two millennia, has been somewhat eclipsed [...]" by the more manageable studies of signalling, pattern 
formation, and gene control [23, p. 4]. To study morphogenesis, contemporary biology employs computational modelling of its processes in combination with experiments verifying the resulting hypotheses. Experimental verification is necessary because "morphogenetic processes cannot be deduced from final form. [...] The fact that a mechanism works on a computer is no [...] itself strong evidence that it works in life; usually, many possible mechanisms will produce the 'correct' result, and only observation of the real embryo will indicate which is used" [23, p. 12, I3]. This danger of making misleading post-hoc conclusions in biology serves as a reminder that architects, as non-specialists, should be particularly careful when claiming that developmental processes in biology are precursors to their designs. This said, however, this paper is principally interested in conceptual models and reasoning that lead to structurally and functionally "correct" results rather than in the underlying molecular processes because these results can be meaningful in the architectural context.

\section{Focus and limitations}

Biological morphogenesis takes multiple forms that differ between kingdoms, phyla, classes, orders, families, genera and species. This diversity provides an overwhelming number of examples that is further multiplied by the co-existence of alternative conceptual understandings. Computational modeling of morphogenesis in biology is a recent approach. Consequently, and despite the natural diversity, only a limited number of available working models is available. At the moment, the existing models tackle simple organisms, often the ones used as models by many biologists. In botany, plants such as Arabidopsis thaliana and Coleochaete orbicularis are commonly used to study generic processes because they are simple and already wellresearched. Furthermore, Coleochaete orbicularis is a $2 \mathrm{D}$ species and the computational modeling of its morphogenesis is geometrically less complex. Given this situation, the biological examples in this paper were selected both for simple pragmatic reasons as well as for their conceptual suitability. A pragmatic stance suggested the selection of models that were sufficiently generic, publicly available and interesting for comparison. Conceptually, a comparison between architectural structures, that are typically immobile, and plants that are also comparatively static seemed less problematic than that with, for example, animals. Cellular structures in the included botanical examples are also visually and structurally similar to those employed in The Parasite project. Consequently, the similarities and differences between them can be more apparent. Again, as was true for The Parasite project, the botanical examples included in this paper are intended as suggestive provocations for possible future work rather than as directly transferrable models or solutions. 


\section{Multi-scale hierarchy}

Dupuy et al. [22] (Figure 7) formalise the structure of a plant by subdividing it into multiple scales. In their model, cell-walls are described at scale I, cells are objects described at scale 2 and tissues are described at scale 3. Entities at different scales of description belong to the same plant and the relationships between them can be described as a hierarchy: cells are made of walls, tissues are made of cells and so on.

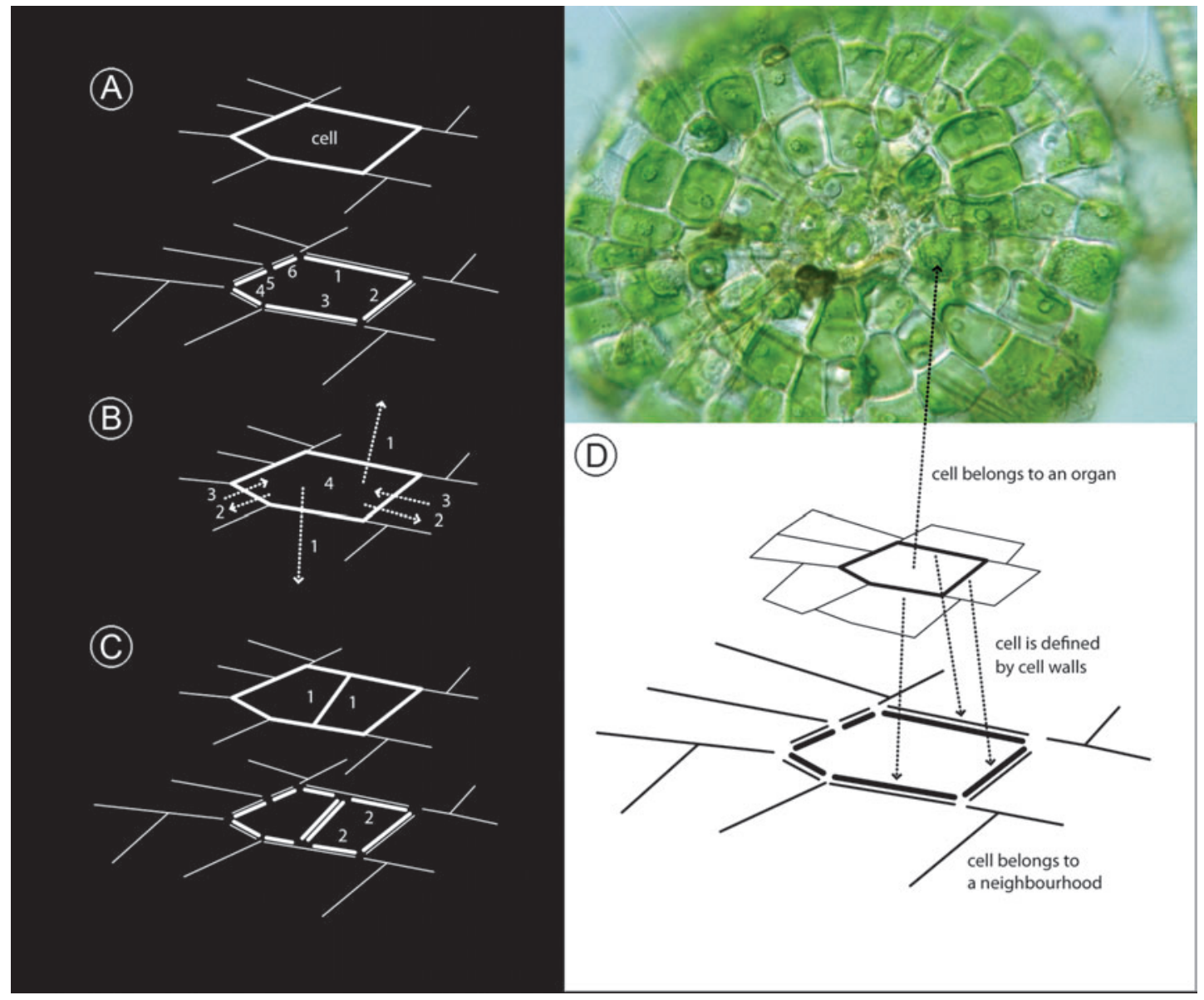

$\Delta$ Figure 7. (A) Cellular architecture of plants can be conceptually subdivided into several scale levels represented in this diagram by horizontal planes. This conceptual subdivision helps to formalise the structure and functioning of plants. (B) The entities in each level of description establish interactions with other plant constituents, and it is possible to determine a topological neighbourhood for any entity: a cell is related to its neighbouring cells horizontally, it belongs to an organ in a vertical upward relationship and to the walls that define its boundaries via a vertical downward relationship. (C) The evolution of such properties is determined by autonomous inter-cell functions and by the functions that determine interactions between entities in the topological neighbourhood. (D) Changes in the network of interactions are due to growth mechanisms and can be broken down into birth and death operators: the division of a cell results from the deletion of four walls and the creation of ten new walls (eight subdivision from previous walls plus the two new walls separating the newly created cell). Entities associated with new walls are then defined through one inheritance function and those associated with the two daughter cells through another. (Conceptual diagrams based on the work of Dupuy et al. [22]; photomicrograph of Coleochaete orbicularis, top right, is by Yuuji Tsukii, Protist Information Server, URL: http://protist.i.hosei.ac.jp/.) 
While additional technical information and the formulae are available in their paper, of interest here is the complex and interconnected hierarchy that underlies the process of morphogenesis. The organisational balance of such a hierarchy can usefully inform Parasite-like structures and provide inspiration for other types of generatively produced architecture.

Interactions between components in complex structures can be expressed as horizontal and vertical relationships. Related components can exchange information. In plants, signalling processes, for example those sustained by chemical transport, can influence cell development, positioning, patterning and differentiation. In architecture, deeper hierarchies of interconnected elements could support similar form-making effects simultaneously supporting continuous automated development, local responsiveness and targeted, non-destructive controlling.

\section{Dynamic structure}

Another significant difference of plant morphogenesis from The Parasite's generative process is that plants' organisations are highly dynamic both in terms of chemical transport between cells and the architectural dynamics of cell development, growth and proliferation. In the architectural context, a functional analogue to the dynamic transport of chemicals through cells could account for the adaptable properties of cell congregations and the influence of this effect could be combined with other influences on cell properties.

In addition to the dynamic diffusion of chemicals between cells, Dupuy et al.'s model [22] can account for dynamic structural changes in the system, for example those occurring when cells divide or die. Their model modifies the cellular structure through operations of creation and deletion. The operation of creation is also responsible for the initiation of cell properties that are controlled by the inheritance function able to account for such concepts as asymmetric division, lineage and other mitotic events. In the architectural context, this capability would be able to support generation of varied geometries in response to explicit instructions or local conditions.

Another dynamic attribute of plant cells is the capability for expansion under turgor pressure (Figure 8). The actual physics behaviour of viscous plant cell-walls can be relevant in architecture only in the application to similar materials. However, the general concept of an expandable cell can further support the dynamic adaptability of the computational model.

\section{Processual continuity}

As is true of all natural processes, biological morphogenesis is continuous. Its processes occur at varying speeds but they never completely halt. Once an organism develops into an adult specimen it continues changing into its phenotype or, "the observable characteristics of an individual resulting from the interaction of its genotype with the environment". Furthermore, "[o]nce 


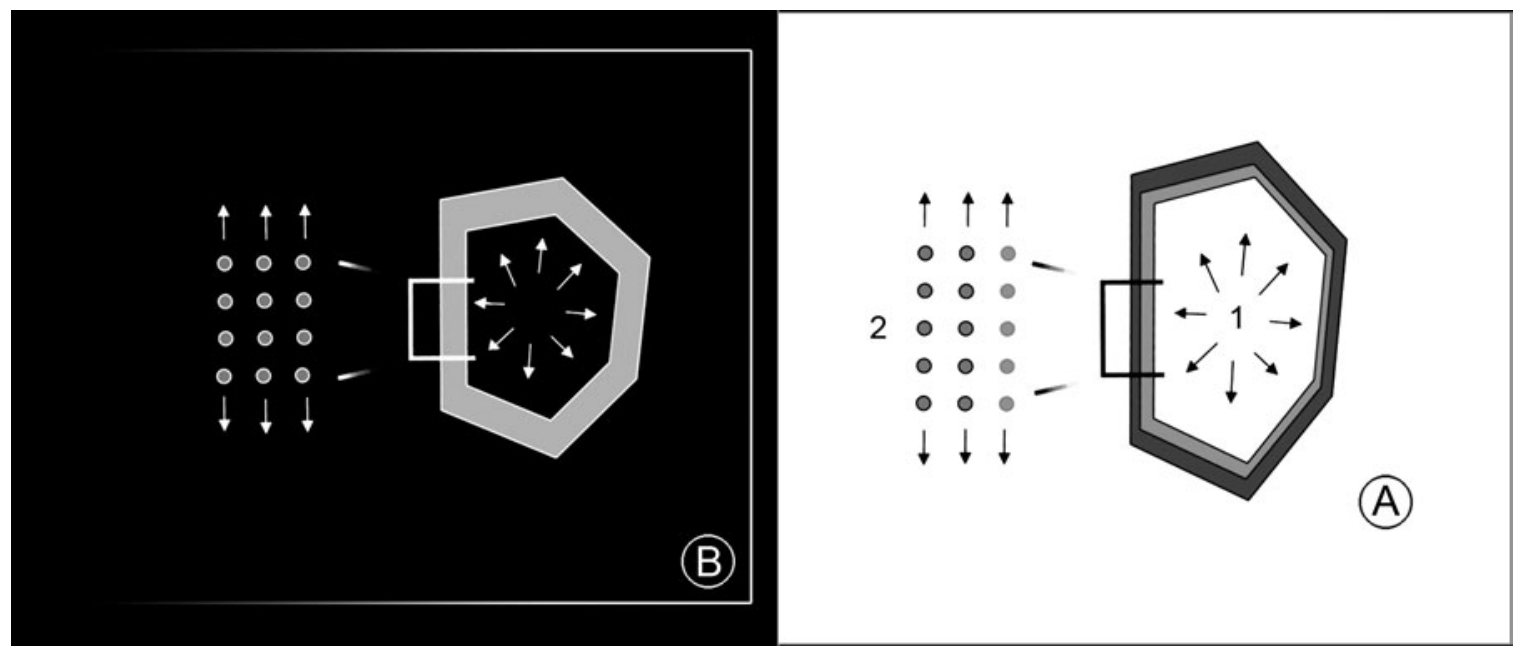

the phenotype has been established, there is further interaction with the genome for regeneration, repair and possible further development" [20, p. 29]. This processual continuity allows a high degree of individual adaptability. As discussed above, greater continuity similar to the one characteristic of living organisms can be beneficial to generative processes in architecture. It is even more interesting to consider how this continuity could be extended beyond the confines of a single design so that architects could both experiment with multiple architectural equivalents of genotypes and extend adaptive capabilities into inhabitable places. However, this discussion is too broad to be considered in this paper.

\section{Examples of morphogenetic models}

The following examples show how different control mechanisms in the computer simulations of plant morphogenesis result in additional structural developments that can be meaningful in the architectural context.

Figure 9 shows differentiation of epidermal cells into trichomes in arabidopsis. In this case, the pattern is triggered by interactions between regulatory genes. While the simulation of the actual genetic mechanism is not relevant to architecture, the ability to procedurally generate various patterns in complex cell congregations can be valuable for a variety of purposes from decorative to structural. Figure 9 shows that a computational model of morphogenesis can variously distribute structural features (in this case - cells) and their properties (in this case - color) in response to an underlying logic.

In another example (Figure 10,A-C), emergence of new organs in plants can be triggered by concentration of hormones in particular locations. Again, the detailed chemistry and mechanics of this hormonal mechanism can be irrelevant in architecture. However, the computer model simulating the process of organ emergence can be suggestive for the development of similar procedural mechanisms for the production of architectural geometry.
A Figure 8. Biomechanical model for cell expansion in morphogenesis: cell wall response to turgor pressure through a viscous yielding of the cell wall, compensated at the same time by thickening to maintain a constant cross-section. (Conceptual diagrams based on the work of Dupuy et al. 
Figure 9. Simulation of trichome distribution in Arabidopsis. (A, B)

Patterns of gene expression obtained from the genetic regulatory network.

(A) Typical distribution of trichomes.

(B) Mutant distribution (conceptual diagrams based on the work of Dupuy et al. [22]). (C) A single Arabidopsis trichome, cryo-scanning electron microscopy image (by Emmanuel Boutet). (D) Arabidopsis, photograph (by Colin Purrington).

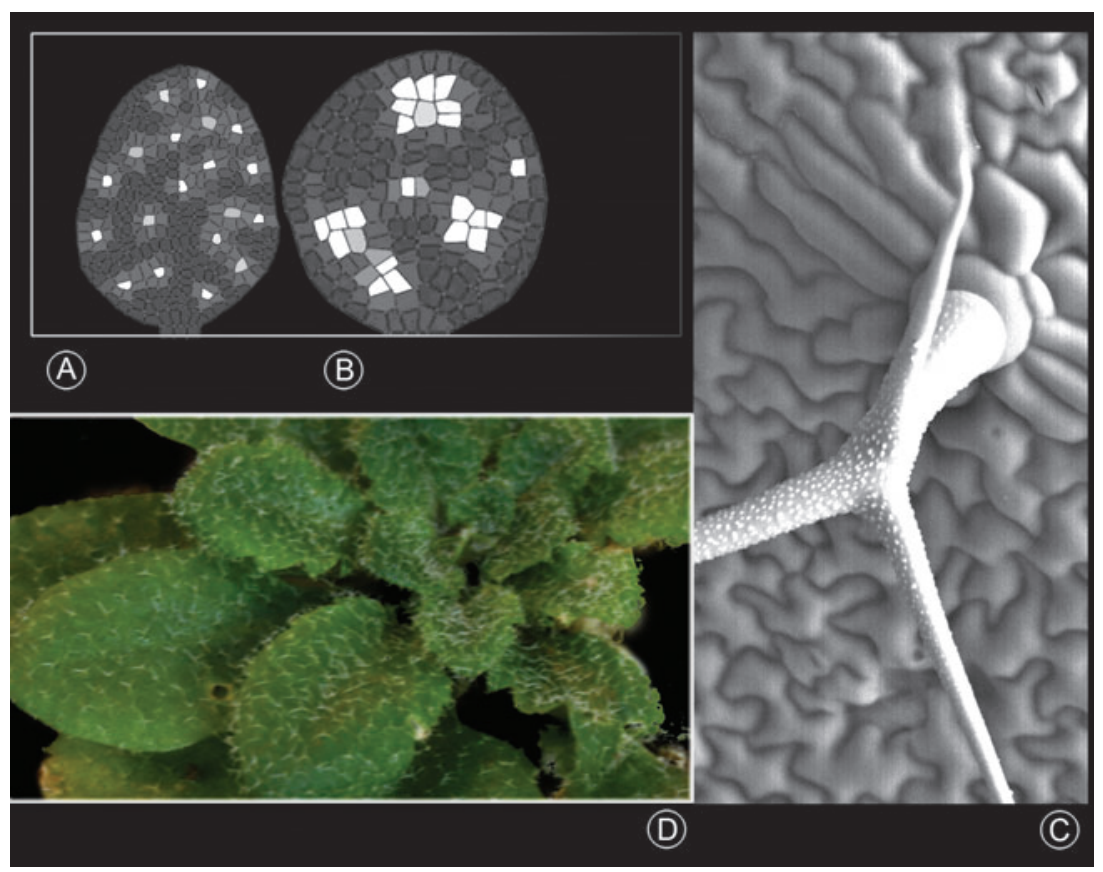

Figure 10. (A-C) Establishment of the 'reverse fountain' cycling of auxin: (A) initial conditions, (B) direction of flux towards the local maxima of auxin concentration; $(\mathrm{C})$ redirection and canalization of the flux towards deeper tissues [22]. (D-G) The influence of mechanical interactions and tissue morphogenesis illustrated by the simulation of an outgrowth generated by three tissues expanding at different rates. A fast-growing tissue (D-F, medium grey) is adherent to two slowly growing surrounding tissues (white, dark grey). (G) Darker areas show higher strain. (Computational simulations based on the work of Dupuy et al. [22])

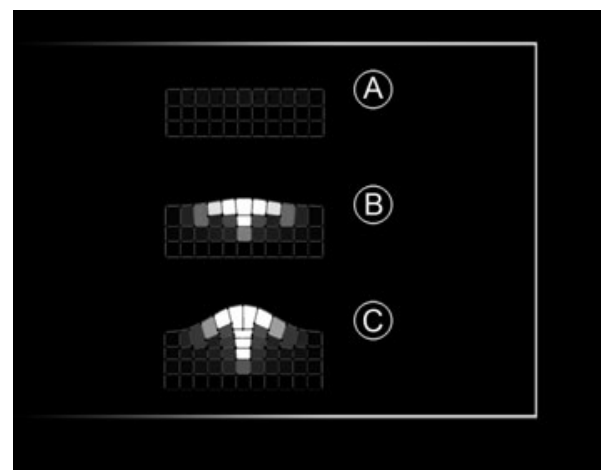

(D)

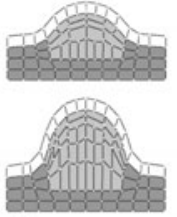

(F)

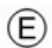

(E)

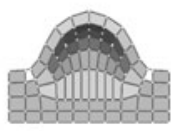

(G)

Yet another example of structure formation is that of an outgrowth appearing under the influence of mechanical interactions (Figure I0, D-G). In the shoot apical meristem, for example, initiations of primordia are accompanied by cell proliferation under the layer in which the primordia are initiated. Expanding cells remain largely adherent to surrounding tissues, and the mechanical behaviour of all tissues influences the kinematics of expansion in the emerging meristem. In the plant morphogenesis simulation [22], the process began when cells were organised in three tissues with separate properties. This mechanism can be transported into the architectural domain in a more literal fashion because it relies on properties, such as rates of proliferation, that can be directly utilised in the design of architectural structures. 


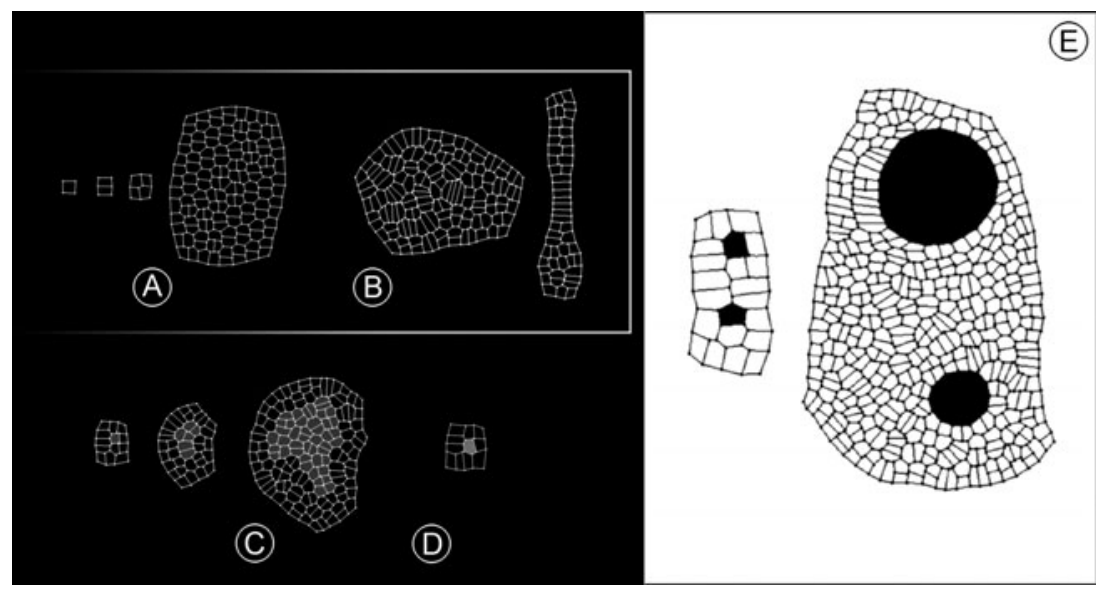

Figure II (A, B) demonstrates further variations in patterning and form achieved through the imposition of rules controlling the direction of cell division while Figure II (E) shows the effects produced when some cells are constrained so that they can expand but not divide. Both effects can be used in architecture with the second one being particularly suggestive. During the development of The Parasite structure we experimented with different techniques that could introduce openings able to function as windows or doors. However, all of our approaches required manual interference and, as such, interrupted the automation. The examples above suggest possibilities for procedural differentiation capable of producing various openings of meaningful sizes and proportions in procedurally selected, meaningful locations.

The selective growth shown in Figure II (C, D) is also suggestive of architectural usages, for example, using this technique it might be possible to adjust the distribution of volumes while preserving the characteristics of the surrounding skin.

Figure 12 provides further examples of control mechanisms including those that are suggestive for the situations where two or more arrangements have to interact. Looking at the examples of cell colonies merging upon contact, it is possible to imagine similar integrations between architectural arrangements.

\section{From biology to architecture}

Examples in this section included computational models of morphogenesis in botany and aimed to suggest how architectural cellular structures similar to that of The Parasite and, possibly, to other architectural arrangements can remain procedural while also becoming more flexible and controllable.

These specific examples are valuable because they describe concrete, working mechanisms. At the same time, they are very narrowly focused. The next section of this paper derives inspiration from these examples and
Figure 13. (A, B) Indeterminate growth organized by inherited polarity. (A) Alternating division axis with growth axis perpendicular. (B) Division axis chosen randomly with growth axis perpendicular. (C, D) Cell proliferation zone (shaded) surrounded by nongrowing cells. (C) Cell maximum strain is 0.1 ; growth is indefinite with surrounding cells stretched. (D) Cell maximum strain is 0.5 ; equilibrium reached and cell proliferation is constrained. (E) Indeterminate growth organized by inherited polarity. Black cells allowed to grow but prevented from dividing. (Computational simulations based on the work of Rudge and Haseloff [19, p. 84]) 


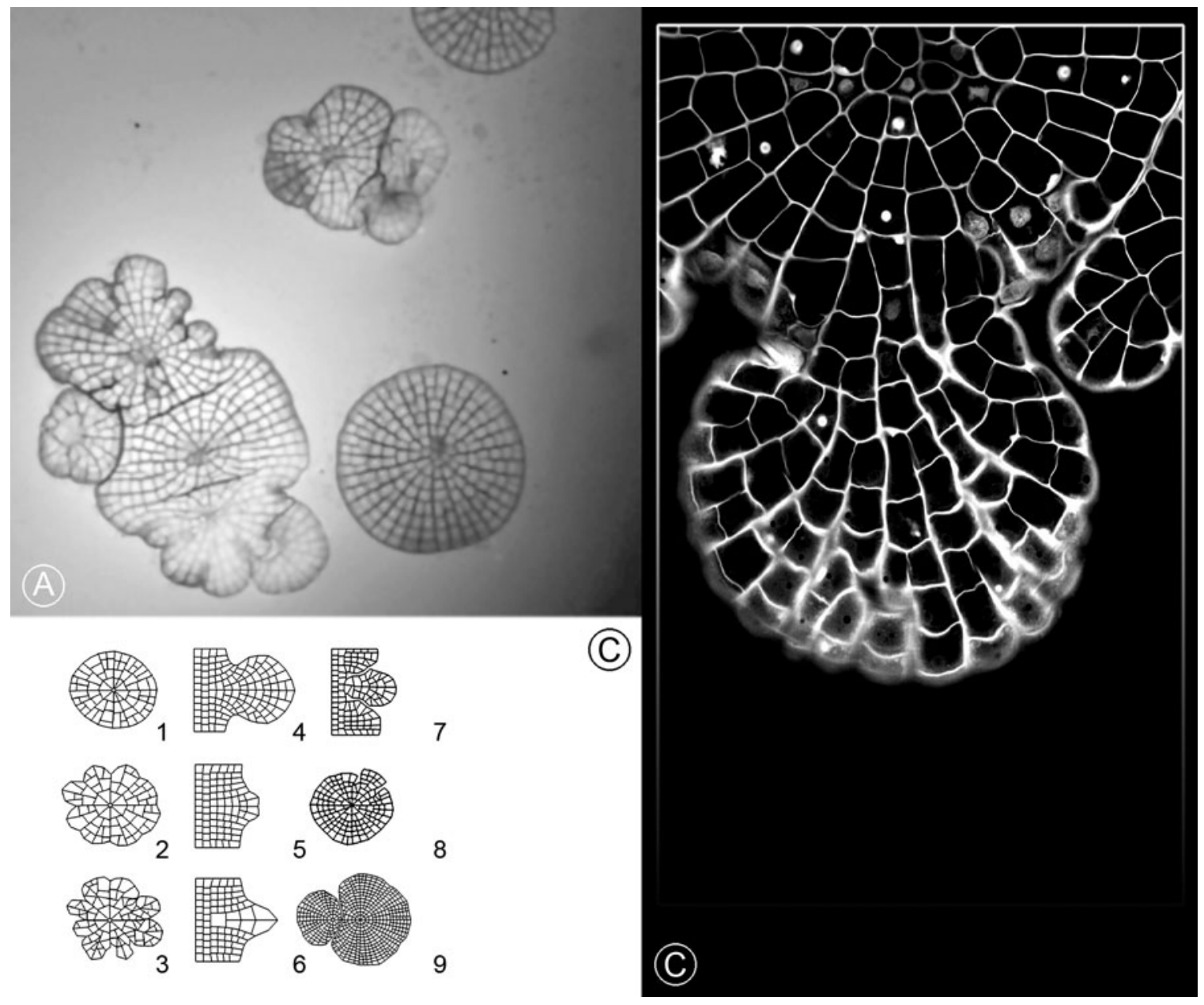

Figure 12. (A) The development of Coleochaete orbicularis. When unconstrained, the plant organizes in one-layer, circular tissues. Other morphologies may appear when contact between several colonies occurs or in the case of injuries. (B) Cell proliferation patterns in various conditions: (I-3) circular growth with various wall bending properties. (4-6) outgrowth resulting from local variation in turgor pressure (4), viscosity (5) and cell size (6). (7-9) outgrowths resulting from the forces released from ablated cells. (9) simulations of colonies getting in contact. (C) A response to cell ablation. (Computational simulations and confocal microscopy images based on the work of Dupuy et al. [24]) reflects on broader biological analogies in architecture, on implications for design and the possible directions for future research work.

\section{Discussion}

Recent, "digital avant-garde" [8, p. 195] experimentation in architecture (and the philosophy it likes to reference) have been criticized for a superficial understanding of concepts borrowed from other disciplines (see Hagan [25] on the "autonomous", self-referential nature of avant-garde in architecture or Sokal and Brichmont [26] on confused borrowings from science) and for a frivolous engagement with the possibilities given by computing resulting in "fake creativity" $[27,28]$. Others claim that a typical importation of forms from biology is purely stylistic rather than functional or that borrowing of forms from biology has been done before and is not innovative. For example, Steadman [29, p. 258] observes that many "architects have been generating 'organic' doubly curved surfaces with the help of software that 
has no basis in biological process or structure [...]. There may be much talk of 'morphogenesis', and a rich stew of other biological concepts invoked, but the truth is that the main analogy with nature is at the level of appearances only, and specifically with the non-rectangularity of nature." This paper suggests that a deeper engagement with the science of biology can generate unique insights and inspirations that can answer some of these criticisms by helping to interlink creative, cultural, functional and green concerns through procedural, generative workflows.

Humans have always tried to understand and imitate nature. Generations of craftsmen, architects and designers have been inspired by nature's creativity [30-35]. Amongst other natural phenomena, life forms were particularly interesting to humans and since the emergence of biology in the early $19^{\text {th }}$ century, many designers have been inspired by its discoveries (see van Eck [36] for a discussion of the $19^{\text {th }}$-century "organicism" or Steadman [29] for a general overview of biological analogy in architecture). Some interpreted biological motifs aesthetically, as ornaments and decorations. Others utilized its symbolic interpretations as philosophical, metaphorical or spiritual foundations of their practice. Pragmatically, many attempted to inform their designs by learning from the organization of natural structures and more recently, an increasingly growing number of practitioners and researchers aim to understand and reinterpret naturally occurring functionalities, behaviors or processes of growth and natural selection (e.g., cf. cellular automata [32], plantgeneration software $[37,38]$ or L-systems.

This architects' attraction to natural systems exists in parallel with a broader interest in biomimicry or bioinspiration as fundamentally differing attitudes towards nature. (Previous efforts with similar goals were undertaken as "biotechnique" or "biotechnics" in 1920s and 1930s as well as "bionics" or "biomimetics" that began in 1950s, as discussed in Steadman [29, pp. xvi, 260].) In the words of Benyus [39], "this time, we come not to learn about nature but to learn from nature so that we might fit in, at last and for good, on the Earth from which we sprang." While Benyus's book casts biomimicry as a philosophical and moral position, most of the research in biomimicry is technical and takes place in engineering or applied sciences.

Bioinspiration is a term that seems more appropriate in relationship to architecture because it emphasizes indirect and multiplicious characteristics of knowledge transfer between biology to architecture. Writing in application to structural engineering, Arciszewski and Kicinger [40, 4I] suggested differentiating between visual, conceptual and computational bioinspiration. These categories can also help to distinguish between biologically inspired architectural designs. In architecture, the visualinspiration category will include projects visually or sculpturally resembling those found in nature [e.g., see 42]. Meaningful outcomes of these projects will rely primarily on the architectural expertise of a designer responsible 
for the selection and interpretation of natural forms. Conceptual inspiration will describe situations where designers will use or reinterpret principles found in nature. For the meaningful results to emerge in this case, designers need to possess and be able to combine the expertise in biology and in architecture. Computational inspiration (or perhaps better - generative inspiration) will refer to computational mechanisms inspired by those observed in nature. These mechanisms, such as evolutionary computation or cellular automata, can simulate the emergence of forms in a computational environment allowing for the adaptation towards specific goals.

Even when architects deal with problems, these problems are "wicked" [43-45] and resist singular solutions. In most cases, however, "problem" is an altogether unsuitable concept to describe the complex pursuits of architectural practice. When the output is understood as addressing concerns, finding opportunities or imagining speculative and contradictory futures, the concept of solution-finding becomes inapplicable. Conceptual, interpretative and subjective contributions are always necessary in architectural designing and in many situations ought to be appreciated amongst the most valuable offerings of the profession.

However, valuing human insight does not have to contradict the contributions possible via generative approaches that can inform human imagination as well as control aspects of design development. In agreement with this position, the biologically-informed cellular structures suggested in this paper can inspire across categories of bioinspiration: visually, they can result in rich, flexible and suggestive ornamentation; conceptually, they can reapply the principles of hierarchical organization and dynamic control found in plants; and generatively, they can help to develop automatically adaptive processes that are better integrated, uninterrupted, unless by choice, and more flexibly controllable.

As Davies discusses [23, p. 13], the emergence of complex, organized structures is not unique to the biological world. Complex patterns exist and overlap in the physical world on many scales, from molecules to star formations. Biological organizations are different from the purely physical systems because they result from and participate in evolution. They have to be sufficiently flexible to remain open to modification by natural selection. Purely physical morphogenesis tends to produce inflexible structures such as crystals. Self-assembly, that is also an important mechanism of biological morphogenesis, is a common process underlying the morphogenesis of nonliving systems. "Self-assembly is the coming together of subunits to make a structure, because their association is energetically favorable and their association reasonably probable [...]" (ibid.). Many physical organizations such as crystals or soap bubbles can take only one optimum form that depends on the given physical conditions. The architectural example given at the beginning of this paper, The Water Cube in Beijing, uses this type of structure in its foam-like forms. So do other well known projects such as 
Antonio Gaudi's La Sagrada Familia with its catenary arches or Frei Otto's architecture of the minimal forms $[46,47]$. While these structures might be optimal to their physical conditions, they are not characterized by fitness for any purpose, behavior or habitat. Their tectonic efficiency, while formally pure, is a poor match to the multiple, contradictory and dynamic concerns of habitation. Even the dynamic physical systems such as, for example, sand dunes are still different from biological ones because their transformations are "dictated simply by the physical attributes of the components involved and not by any feedback from how well the form is adapted to function, because there is no function." [23, p. 13, 14]

These examples are relevant in the context of recent experimentation with parametric and procedural, computer-sustained strategies in architecture. Architects experimenting with these technologies and the discourse surrounding these experiments often claim Gaudi and Otto as direct ancestors, especially when talking about emergence or finding of form. In these discussions, often it is the static performance that is primarily considered. As Menges writes [48, p. 79], "form-finding, as pioneered by Frei Otto, is a design technique that utilises the self-organisation of material systems under the influence of extrinsic forces.'[49-5I]. Alternative understandings of form finding do exist in practice. For example, the configuration of Norman Foster's roof for The British Museum was determined by the goal of visual continuity, rather than structural performance. To achieve this aesthetic rather than tectonic effect, visually identical structural members were given dramatically different wall thicknesses [52].

In extension to the capabilities of purely physical organizations, biological organizations are capable of "adaptive self-organization" (analogical terms are swarm intelligence, hive intelligence, distributed optimization or adaptive routing). Enabled by the capabilities to receive and react to multiple layers of negative feedback, "systems that show adaptive self-organization can arrange their structures in ways not simply dictated by the properties of the structures' subunits, but also according to the (unpredictable) environment in which they find themselves" [23, p. 14]. (Negative feedback is a term used in biology and in cybernetics. In biology, negative feedback is usually referred to as homeostasis, other disciplines use such terms as equilibrium, attractors, stable states, eigenstates/eigenfunctions, equilibrium points, and setpoints. Examples of negative feedback include hormonal regulation, temperature regulation in animals and thermostat control in man-made artefacts.)

Given these capacities for adaptive self-organization, biological morphogenesis templates, such as those discussed in this paper, promise to offer more flexible solutions to architectural design than those offered by current form finding approaches characterized by flatter, less dynamic and, therefore, less responsive organizational hierarchies (such as those of The 
Parasite or The Water Cube). In particular, the benefits in the architectural field might include:

- Support for extra complexity. For the structures to become more flexibly adaptable, their complexity will have to increase. For example, the components of The Water Cube structure are standardized and only appear complexly random when viewed from arbitrary angles. This standardizing limits the capacity for local responsiveness. More complex structures are also formally, aesthetically and conceptually more interesting in architecture.

- Amplified imagination. In the creative-practice discourse, morphogenesis has been discussed in relationship to fractals, evolutionary development and cellular automata. The benefits of the concept in the context of creative practice include algorithmic visual creation, potentially leading to unusual results.

- Safe and flexible environment for experimentation. When design proposals can be generated, evaluated and adjusted as digital simulations, they can better, more easily and more safely respond to dynamic and contradictory local conditions.

- Procedural integration with environmental simulation, evaluation and design tools. Flexibility given by a fully generative, dynamic approach that can inform the development of form at multiple levels of the hierarchy can help to derive structures able to respond to needs for comfort, amenity, energy, climate responsiveness and environmental impact. Environmentally efficient design solutions can be counterintuitive, especially in situations where there are complex patterns of usage and unusual building forms. Integration of analysis with the flexibility of a generative approach to form-making can help to explore the benefits of configurations that would otherwise be overlooked.

- Enhanced ability to adjust the design at different points of the procedural chain, non-distractively and with greater flexibility. Experimentation with alternative designs (versioning) and adjustments to complex performance criteria can be achieved more easily, saving time, money and allowing designs that could not otherwise be practicable because of their complexity or the effort required for their adaptation. In The Parasite project, we developed some techniques for fine-tuning the geometry of the structure without the need for a full regeneration. However, these techniques were limited and comparatively inflexible. This inflexibility is a necessary characteristic of all generative systems with shallow hierarchies. A multi-level hierarchy can allow the production of alternative versions of geometry or fine-tune components at the lower levels of the hierarchy without the need to regenerate the 
already-acceptable configurations achieved at the higher levels.

- Use of complex and adaptable cellular structures can have structural benefits in architecture. Even though less flexible in adaptation than biological analogues, 3D Voronoi patterns already suggest such possibilities [53]. Exploration and selective utilization of biological principles promises additional benefits in structural engineering as it attempts to respond to the demands for more complex configurations and seeks innovative approaches to construction.

\section{Future work}

A deeper engagement with biological understandings of morphogenesis via investigative designing will be essential for the development of these ideas and this paper establishes a foundation for future work that will look at the experimental implementations of these approaches in architectural contexts. The purpose of this paper is to establish a framework for this further development and to invite others to consider the possibilities that can emerge from a purposeful knowledge transfer between biology and architecture with the ambition for this transfer to go beyond metaphorical analogies towards engagement with formal models and computational techniques.

In relationship to one-organism growth and adaptation (parallel to cultivation or training in agriculture or gardening, such as the impressive, if somewhat disturbing, array of plant-forming techniques used in bonsai where unusual sizes and shapes of trees and shrubs are created and maintained through leaf trimming, pruning, wiring, clamping, grafting, defoliating and simulating deadwood [54]), future work will identify additional procedural operations that could assist non-reductive manipulation of complex configurations by simultaneously providing control mechanisms and supporting automatic adaptation. This work will contribute to a taxonomy of process-oriented techniques and develop practical, reusable implementations and prototypes. Similarly to the compendiums of traditional compositional principles, a taxonomy of process-based approaches might be useful as a reference guide as well as an indicator of unobvious knowledge gaps.

Another research direction will investigate evolutionary adaptation across generations using algorithms responding to a broad range of fitness criteria in combination with the developmental adaptation as mentioned above. In this area, the existing work in architecture is sparse and has been oriented towards fully automated designing that has prioritized physical efficiencies over cultural concerns.

The proposed collaboration with botanists can be beneficial to both parties. While the architects can extend their models conceptually and benefit from existing formalisms and techniques in computational simulations of plant structures, botanists also can benefit from engagement 
with architects and engineers because they want to extend their models to operate in three dimensions, make them more dynamic and able to simulate mechanic (static, dynamic and fluid) and other physical processes. In these tasks, they can benefit from the existing expertise in architecture and engineering.

\section{Conclusion}

This paper has considered existing understandings of morphogenesis in architectural design and biology by discussing examples of cellular, computationally-generated structures, one of an architectural installation and several others constructed to represent morphogenesis in plants. The comparison between the cellular arrangements and the respective modes of production in these case-studies demonstrated that plant morphogenesis is characterised by complex and flexible mechanisms that can suggest interesting directions for the development of procedural techniques in the architectural domain. Amongst these directions were: I) implementation of a multi-level hierarchy reflecting functional and structural composition of an architectural arrangement similar to that describing the organisation of a plant; 2) implementation of a capability for dynamism in the exchange of signals between cells; and 3) implementation of another kind of dynamism that can account for topological changes through the deletion and creation of cells. Illustrated examples of computational models simulating effects of various control mechanisms in plants demonstrated practical effects of selective growth capable of producing architecturally meaningful forms.

\section{Acknowledgements}

The work of designing and building The Parasite project was done at the Digital Studios of the Department of Architecture, University of Cambridge. Giorgos Artopoulos was the project's co-author and is co-responsible for The Parasite's images included in this paper. The computational models of plant morphogenesis referred to in this paper were built in Jim Haselhoff's lab at the Department of Plant Sciences at the University of Cambridge. Jonathan Mackenzie who was responsible for the programming of these models is an important collaborator who has contributed to the development of the ideas discussed above. The future research work suggested in this paper will be developed with his direct participation.

\section{References}

I. Carfrae, T., Engineering The Water Cube, Architecture Australia, 2006, 95(4), 103105.

2. Macarthur, J. and Crist, G., Federation Square, Architecture Australia, 2003, 92(2), 46-64.

3. Murray, S., Melbourne Recital Centre, Melbourne Theatre Company, Architectural Review Australia, 2008, (108), 57-67. 
4. Schlueter, A. and Bonwetsch, T., Design Rationalization of Irregular Cellular Structures, International Journal of Architectural Computing, 2008, 6(2), 197-2II.

5. Krippendorff, K., The Semantic Turn: A New Foundation for Design, Taylor \& Francis CRC, Boca Raton, FL; London; New York, 2006.

6. Heape, C.R.A., The Design Space:The Design Process as the Construction, Exploration and Expansion of a Conceptual Space, PhD Thesis, Mads Clausen Institute, University of Southern Denmark, Sønderborg, 2007.

7. Kolarevic, B., Digital Morphogenesis and Computational Architectures, Proceedigns of the 4th Confernece of Congreso Iberoamericano de Grafica Digital, SIGRADI 2000 Construindo (n)o Espaço Digital (Constructing the Digital Space) [ISBN 85-88027-02$X]$, Rio de Janeiro (Brazil) 25-28 September 2000, 2000, 98-103

8. Kolarevic, B. and Malkawi, A., Performative Architecture: Beyond Instrumentality, Spon Press, New York; London, 2005.

9. Hensel, M., Menges, A. and Weinstock, M., Emergence: Morphogenetic Design Strategies, Wiley, London, 2004.

10. Weinstock, M., Self-Organisation and Material Constructions, Architectural Design, 2006, 76(2), 34-4I.

II. Hensel, M. and Menges, A., Differentiation and Performance: Multi-Performance Architectures and Modulated Environments, Architectural Design, 2006, 76(2), 6069.

12. Weinstock, M., Self-Organisation and the Structural Dynamics of Plants, Architectural Design, 2006, 76(2), 26-33.

13. IArtopoulos, G. and Roudavski, S., It's a Parasite!, (Eds. I. Hartmann, S. Michajlová and K. Rybková). in: International Biennale of Contemporary Art 2005 - National Gallery in Prague, Národní galerie v Praze, Prague, 2005, I22- 123.

14. Artopoulos, G., Roudavski, S. and Penz, F., Adaptive Generative Patterns, Proceedings of The Second International Conference of the Arab Society for Computer Aided Architectural Design (ASCAAD 2006), The Arab Society for Computer Aided Architectural Design (ASCAAD), Sharjah, 2006, 34I-362

15. Artopoulos, G. and Roudavski, S., It's a Parasite! Prague Biennale Pavilion, Metalocus, 2006, I8.

16. Roudavski, S., Artopoulos, G. and Penz, F., Digital Design Techniques for Adaptable Systems: Prague Biennale Pavilion, GameSetAndMatch II:The Architecture CoLaboratory on Computer Games, Advanced Geometries and Digital Technologies, Episode Publishers, Rotterdam, 2006, 478-486

17. Roudavski, S., Staging Places as Performances: Creative Strategies for Architecture, PhD Thesis, University of Cambridge, Cambridge, 2008.

18. Waddington, C.H., Principles of Embryology, Allen and Unwin, London, 1956.

19. Rudge, T. and Haseloff, J.P., A Computational Model of Cellular Morphogenesis in Plants, (Eds. R. Goebel, J. Siekmann and W.Wahlster). in: Advances in Artificial Life, Lecture Notes in Artificial Intelligence, Vol. 3630, Springer, Heidelberg, 2005, 7887.

20. Cowin, S.C. and Doty, S.B., Tissue Mechanics, Springer, New York, 2007.

21. Sachs, T., Pattern Formation in Plant Tissues, Cambridge University Press, Cambridge, 1991.

22. Dupuy, L., Mackenzie, J.P., Rudge, T. and Haseloff, J.P., A System for Modelling CellCell Interactions during Plant Morphogenesis, Annals of Botany, 2008, I0I(8), |255-| 265.

23. Davies, J.A., Mechanisms of Morphogenesis, Elsevier Academic Press, Amsterdam, 2005. 
24. Dupuy, L., Mackenzie, J.P. and Haseloff, J.P., A Biomechanical Model for the Study of Plant Morphogenesis: Coleocheate Orbicularis, a 2D Study Species, Proceedings of 5th Plant Biomechanics Conference - Stockholm, August 28 - September I, 2006, STFI-Packforsk AB, Stockholm, 2006,

25. Hagan, S., Digitalia:Architecture and the Digital, the Environmental and the Avantgarde, Routledge, London, 2008.

26. Sokal,A.D. and Bricmont, J., Fashionable Nonsense: Postmodern Intellectuals'Abuse of Science, Picador, New York, 1999.

27. Lawson, B., 'Fake' and 'Real' Creativity using Computer Aided Design: Some Lessons from Herman Hertzberger, Proceedings of the 3rd Conference on Creativity \& Cognition, ACM Press, New York, 1999, 174- 179

28. Lawson, B., CAD and Creativity: Does the Computer Really Help?, Leonardo, 2002, 35(3), 327-331.

29. Steadman, P., The Evolution of Designs: Biological Analogy in Architecture and the Applied Arts, Routledge, New York, 2008.

30. Aldersley-Williams, H., Zoomorphic: New Animal Architecture, Laurence King, London, 2003.

31. Feuerstein, G., Biomorphic Architecture: Human and Animal Forms in Architecture, Axel Menges, Stuttgart; London, 2002.

32. Frazer, J.H., An Evolutionary Architecture, Architectural Association, London, 1995.

33. Jodidio, P., Architecture: Nature, Prestel, Munich; New York, 2006.

34. Senosiain, J., Bio-architecture, Architectural Press, Oxford, England, 2003.

35. Tsui, E., Evolutionary Architecture: Nature as a Basis for Design, John Wiley, New York, 1999.

36. van Eck, C., Organicism in Nineteenth-Century Architecture:An Inquiry into its Theoretical and Philosophical Background, Architectura \& Natura Press, Amsterdam, 1994.

37. Dollens, D., Digital-Botanic Architecture, SITES Books, Santa Fe, NM, 2005.

38. Dollens, D., A System of Digital-Botanic Architecture, Leonardo, 2005, 38(I), I521.

39. Benyus, J.M., Biomimicry: Innovation Inspired by Nature, Morrow, New York, 1997.

40. Arciszewski, T. and Kicinger, R., Structural Design Inspired by Nature, (Eds. B.H.V. Topping). in: Innovation in Civil and Structural Engineering Computing, Saxe-Coburg Publications, Stirling, UK, 2005, 25-48.

4I. Arciszewski, T. and Kicinger, R., Breeding Better Buildings, American Scientist, 2007, 95(6), 502-508.

42. Portoghesi, P., Nature and Architecture, Skira Editore; Thames \& Hudson, London; Milan, 2000.

43. Rittel, H.W.J., On the Planning Crisis: Systems Analysis of the 'First and Second Generations', Bedrifts Okonomen, 1972, (8), 390-396.

44. Buchanan, R.,Wicked Problems in Design Thinking, Design Issues, 1992, 8(2), 5-2I.

45. Coyne, R.,Wicked Problems Revisited, Design Studies, 2005, 26(I), 5-17.

46. Otto, F., Rasch, B. and Werkbund Bayern, Finding Form:Towards an Architecture of the Minimal, Axel Menges, Stuttgart, 1995.

47. Otto, F., Nerdinger,W. and Technische Universität München, Frei Otto: Complete Works: Lightweight Construction, Natural Design, Birkhäuser, Basel; Boston, 2005.

48. Menges, A., Polymorphism, Architectural Design, 2006, 76(2), 78-87. 
49. Felicetti, P., Xie, M., Tang, J. and Huang, X., Application of Evolutionary Structural Optimization Techniques to Architectural Structures, GameSetAndMatch II:The Architecture Co-Laboratory on Computer Games, Advanced Geometries and Digital Technologies, Episode Publishers, Rotterdam, 2006, 345-359

50. Shea, K., Aish, R. and Gourtovaia, M., Towards Integrated Performance-Based Generative Design Tools, eCAADe 2001- 19th International Conference on Architectural Information Management, Helsinki University of Technology, Helsinki, 200I, 553-560

5I. Shea, K., Directed Randomness, (Eds. N. Leach, D. Turnbull and C.Williams). in: Digital Tectonics, Wiley-Academy, Chichester, 2004, 89-I0I.

52. Woodbury, R., Williamson, S. and Beesley, P., Parametric Modelling as a Design Representation in Architecture:A Process Account, 2006.

53. Friedrich, E., Hanna, S. and Derix, C., Emergent Form from Structural Optimisation of the Voronoi Polyhedra Structure, Proceedings of GA2007, X Generative Art International Conference, Milan Polytechnic, Milan, 2007,

54. Kawasumi, M., II and Kawasu, M., III, The Secret Techniques of Bonsai:A Guide to Starting, Raising, and Shaping Bonsai, Kodansha International, Tokyo, 2005.

\section{Stanislav Roudavski}

University of Melbourne

Faculty of Architecture, Building and Planning

The University of Melbourne,

Melbourne,Victoria 3010, Australia

stanislav.roudavski@cantab.net 


\section{University Library}

\section{- M M I E R R A A gateway to Melbourne's research publications}

Minerva Access is the Institutional Repository of The University of Melbourne

Author/s:

Roudavski, S

Title:

Towards Morphogenesis in Architecture

Date:

2009-09-01

Citation:

Roudavski, S. (2009). Towards Morphogenesis in Architecture. INTERNATIONAL JOURNAL OF ARCHITECTURAL COMPUTING, 7 (3), pp.345-374. https:// doi.org/10.1260/147807709789621266.

Publication Status:

Published

Persistent Link:

http://hdl.handle.net/11343/26591 